\title{
La Iglesia católica \\ mexicana en un mundo \\ global
}

\author{
Jean Meyer ${ }^{1} \quad$ The Mexican Catholic Church in a global \\ jean.meyer@cide.edu • world
}

\section{Resumen}

Síntesis panorámica, en una perspectiva mundial, de las vivencias de los católicos mexicanos y de su Iglesia desde fines del siglo XIX hasta hoy, desde la antigua situación de monopolio religioso de una Iglesia estrechamente ligada a la gran institución eclesiástica transnacional de la Santa Sede hasta el pluralismo actual, marcado por el surgimiento de iglesias evangélicas. Un fenómeno nacional, continental y mundial que obedece a los grandes cambios de los últimos cincuenta años.

Palabras clave: Iglesia católica, protestantismo, globalización, Vaticano, papa.

\section{Abstract}

An essay of synthesis, in a global perPope, changes induced by Vatican II spective of World history, of the sometimes progressive and sometimes violent and results of the competition between a Church that had enjoyed a religious changes produced in the religious life of monopoly since the XVIth century and the Mexican Catholics and their Church; changes produced by decisions of the the young and dynamic Evangelical Churches.

Holy See, i.e. the Roman Curie and the

Key words: Catholic Church, Protestantism, Globalisation, Vatican, Pope. División de Historia, Centro de Investigación y Docencia Económicas, México. Carretera México-Toluca 3655, Álvaro Obregón, Lomas de Santa Fe, CP 01210, México D.F. 


\section{Introducción}

Más que un artículo, este trabajo es un ensayo sobre un tema muy delimitado, a partir de un conjunto de documentos que corresponden al objeto de una investigación precisa. Es un intento de síntesis, de vista panorámica en una perspectiva mundial, de las vivencias de los católicos mexicanos y de su institución religiosa. México no es una isla y su Iglesia católica (lo que significa etimológicamente universal) es romana, por lo tanto ligada, estrechamente ligada, a una gran institución eclesiástica transnacional. El autor ha empleado para tal fin sus investigaciones anteriores, concretadas en artículos y libros, su conocimiento de los archivos que se fueron abriendo poco a poco a lo largo de los años en México, Washington, París, Roma; también ha movilizado su memoria, puesto que desde 1965 ha identificado su destino con el de México y ha podido observar directamente los grandes cambios del reciente medio siglo.

En la primera etapa del siglo xx la esfera religiosa en México conoció una historia turbulenta, incluso violenta, con el enfrentamiento final entre el Estado revolucionario y la Iglesia católica, capítulo último del conflicto clásico que encontramos en todo el mundo católico latino desde el Siglo de las Luces hasta mediados del siglo xx. En este drama, la Iglesia católica, que ocupaba todavía un sitio de casi monopolio en cuestión de fe, encontró al lado del Estado anticlerical unas pequeñas iglesias protestantes, situación que repetía el esquema concebido en la época de Juárez y reconducido por los liberales, luego por la facción revolucionaria triunfante. Durante los años aquellos, entre 1914 y 1938, la Iglesia católica, si bien fue sometida a rudas pruebas, no cedía terreno a unas iglesias protestantes que gozaban del apoyo de todos los gobiernos, tanto el federal como los locales, menos en el Tabasco de Garrido Canabal, "enemigo personal de Dios". Habrá que insistir en las repercusiones del conflicto religioso en el mundo entero, las solidaridades internacionales, en particular por parte de la Iglesia y de los católicos de los vecinos Estados Unidos, y la mediación diplomática de varias naciones.

Cuando la Revolución baja del caballo y se sube al coche, para hablar como Luis González, el panorama cambia: a finales de los años 1950, el proselitismo protestante, que fracasaba desde 1830, encuentra sus primeros y rápidos éxitos en el Sureste, en contacto con Guatemala y en un marco continental latinoamericano. Eso no deja indiferente al arzobispo de San Cristóbal, Samuel Ruiz, a la hora del Concilio. 
Vaticano II es la segunda sacudida que conoce la Iglesia católica mexicana; más prudente en general, más tranquila que sus hermanas de Brasil o Chile. La memoria del conflicto religioso tiene sus efectos, hasta que el compromiso con los pobres y la teología de la liberación radicalizan a cierto número de sacerdotes, religiosos, seminaristas y laicos. La lucha armada en México, Centroamérica y América del Sur atrae más a los católicos que a los protestantes.

La tercera sacudida se llama "modernización" o "secularización", con los grandes fenómenos sociales que son la migración del campo a la ciudad y el gran éxodo continental que lleva a los mexicanos hacia los Estados Unidos. La Iglesia católica, a finales del siglo, ha perdido su monopolio multisecular, a pesar de que conserva una aplastante mayoría. Quizá más importante aún que el progreso de los evangélicos es la gran mutación sociocultural que, con los nuevos medios masivos de comunicación, la urbanización, los cambios de esquemas de conducta social, familiar, sexual, modifican profundamente la situación de la religión: existe un gran supermercado de la religión, en libre servicio, que se manifiesta tanto por la entrada de los telepredicadores brasileños y de sus iglesias, que proclaman que "no debes sufrir" y "debes ser rico", que por las conversiones al budismo, islam, judaísmo, o la emergencia de cultos a Juan soldado, Malverde o la santa muerte.

\section{El conflicto religioso en su dimensión externa}

\section{Antes del conflicto}

A finales del siglo XIX, la elite del clero mexicano - muchos de los futuros obispos salen de su seno- empieza a formarse en Roma, en el famoso Pontificio Colegio Pío Latino Americano, en el proceso de "romanización" que, a partir de 1870 (Concilio Vaticano I y desaparición de los Estados Pontificios), transforma a la Iglesia en general; el Concilio Plenario Latinoamericano de 1899, reunido en Roma, pone en contacto a los obispos mexicanos con los del resto del continente.

La ruda separación de la Iglesia y del Estado en Francia, en 1905-1906, que provoca la expulsión de congregaciones y órdenes religiosas, hace que lleguen a México cientos de sacerdotes franceses, monjas y hermanos educadores. La nueva y fuerte influencia romana, con la "doctrina social de la Iglesia", y la llegada masiva de los franceses se conjugan para dinamizar a los católicos mexicanos, que se lanzan al sindicalismo, a la política (Partido Católico Nacional fundado en 1911), a la Acción Católica. 


\section{El exilio como contacto forzoso con el mundo exterior}

El clero mexicano sufrió tres olas sucesivas de expulsiones o huídas entre 1914 y 1919, luego de 1926 a 1929 a la hora de la Cristiada, y finalmente de 1931 a 1938. En cuanto al pueblo mexicano, salió masivamente hacia los Estados Unidos en dos etapas: 1913-1919 y 1926-1929; cerca de un millón de personas en la primera, más de dos millones en la segunda. No hubo tercera porque la Gran Depresión devolvió a México un millón de mexicanos y cerró la entrada a los EEUU. La mayoría de los obispos tuvo que salir en uno u otro momento; cientos de sacerdotes hicieron lo mismo. Conocieron así los Estados Unidos, Cuba, Guatemala, Colombia, incluso Europa: por ejemplo, muchos seminaristas terminaron o hicieron sus estudios en España, Bélgica, Francia e Italia.

\section{El conflicto religioso en un contexto global}

\section{El cisma en Rusia}

La violencia del choque entre la Iglesia y el Estado en México, en 1926, y el levantamiento popular de los cristeros no se entienden sin la terminante prohibición que Roma hace a los obispos de acatar la Ley Calles. Varios obispos, si no es que la mayoría, habrían esperado que pasara la tormenta e intentado acomodarse con la nueva reglamentación. No hubiera sido la primera vez en la historia de México. Pero resulta que Roma tenía, y tiene, una visión global del mundo y seguía con atención los acontecimientos soviéticos, en el preciso momento cuando llegaba a México la primera embajadora soviética, Alejandra Kolontai.

En Rusia, en la primavera de 1922, un grupo de sacerdotes ortodoxos, apoyado por el OGPU, ${ }^{2}$ denunció a la jerarquía después del arresto del patriarca Tijón y proclamó su identificación con la revolución bolchevique. Manipulado e instrumentalizado por los comunistas, el movimiento "renovador" se desarrolló rápidamente y formó la "Iglesia viva" (Zhivaya Tserkov), la única reconocida por el poder soviético entre 1922 y 1927. Esa iglesia tuvo una seria base eclesiástica, como la tuvo la Iglesia constitucional en tiempos de la Revolución francesa, algo que Roma recordaba; en su apogeo pudo contar con 11000 sacerdotes: verdadera lucha de clases en el seno del clero, esa Iglesia opuso a buen número de sacerdotes a los obispos; el proletariado de los sacerdotes casados, a la elite de obispos y monjes; hay que saber que en las Iglesias ortodoxas los obispos

2 El Directorio Político Unificado del Estado, policía secreta de la URSs hasta 1934. 
se reclutan entre los monjes, porque para ellos el celibato es obligatorio. Al mismo tiempo, el poder soviético arrestó o fusiló a varios obispos.

El cisma ruso, si bien no entristeció a una Roma que veía en la destrucción del zarismo primero, luego de la Iglesia Ortodoxa, el preludio a la reunión de los ortodoxos con los católicos, despertó la excelente memoria histórica de sus dirigentes: el fantasma de la Revolución francesa y de un cisma que duró hasta que Napoleón dictara un Concordato. Por eso, y a la luz de lo que pasaba en la URSS, Roma prestó una atención extrema al intento de cisma en México en 1925, cuando unos gobernantes (Luis N. Morones y el grupo de la CROM) fundaron una "Iglesia católica apostólica mexicana". No prosperó; pero como la Ley Calles imponía el registro de los sacerdotes en la Secretaría de Gobernación, Roma temió la repetición de la historia soviética, a saber, que el poder diera el registro y el uso de los templos únicamente a los cismáticos. ${ }^{3}$

\section{Las naciones frente al conflicto mexicano}

Las naciones frente al conflicto religioso en México, 1926-1929, ${ }^{4}$ libro colectivo publicado en 2010, cuenta esa historia en trece países y menciona otros tantos, hasta Siria, Líbano, Palestina, Filipinas, Indochina y la Unión Soviética. En 2008 publiqué La cruzada por México. Los católicos de Estados Unidos y la cuestión religiosa en México. ${ }^{5}$ El tema es multidimensional: proyección internacional del conflicto y de México, devolución a México de este eco y de la solidaridad de los católicos del mundo, emoción provocada por el fusilamiento del P. Miguel Agustín Pro, S.J., inmediatamente venerado como mártir en todo el mundo católico. Entonces surgió una intensa propaganda católica en forma de prensa: libros, folletos, tarjetas postales, proyecciones, conferencias, y la contrapropaganda de las embajadas y de los consulados mexicanos, así como de los que simpatizaban con el anticlericalismo del gobierno. Cada comunidad católica vivió la crisis en función de su religiosidad propia y del contexto nacional. Así, los católicos alemanes comparaban a Calles con Bismarck y el conflicto con la Kulturkampf; los franceses lo comparaban con su primer ministro Combes y asimilaban los cristeros a los rebeldes de la Vendée de 1793; en otros países, los católicos veían en la crisis mexicana la advertencia de un futuro posible y trágico: así en Argentina, Colombia, Chile, España, Polonia. En Inglaterra, y

3

Meyer, "Dos revoluciones", pp. 89-95; Krasnov-Levitin y Shavrov, Ocherki po istorii russkoi tserkovnoi smuty.

Meyer (comp.), Las naciones.

Meyer, La cruzada. 
en la recientemente independizada Irlanda, la figura del Padre Pro resucita al olvidado Edward Campion, jesuita como él, formado en Bélgica como él, mártir como él, y despierta la dolorosa memoria de las persecuciones sufridas por los católicos desde los Tudor hasta fechas recientes.

Existe una presencia subliminal del conflicto religioso y de la Cristiada en la película inacabada de Serguei Mijailovich Eisenstein ;Que viva México! Es la tesis que sostiene con brillantez Aurelio de los Reyes en El nacimiento de ¡Que viva México! Los libros y las fotos que Eisenstein se llevó de México, y que se encuentran en su museo de Moscú, demuestran que tenía gran interés en la religiosidad mexicana y los cristeros. La Virgen de Guadalupe ocupa un lugar impresionante entre sus adquisiciones bibliográficas, y no es casualidad que haya empezado a filmar el 11 de diciembre de 1930, justo cuando comenzaban las festividades guadalupanas del gran día Doce, y que al año siguiente, en diciembre de 1931, haya captado los festejos del IV centenario de las apariciones en el Tepeyac. En el Museo Eisenstein están una foto de la frase "¡Viva Cristo Rey!" y también la de los católicos ahorcados a lo largo de la vía del tren, publicada en el mundo entero. Eisenstein pintó un Varón de Dolores y escribió: ¡"Viva Christo [sic] Rey"!

A lo largo del conflicto, Roma llamó de manera insistente a la Iglesia universal para que México estuviese presente en las oraciones de los fieles. El principio de la universalización de la figura de la Virgen de Guadalupe está ligado con los acontecimientos mexicanos, como lo demuestra el caso del cura italiano Capella, fusilado en octubre de 1944 por los S.S., invocando a "la Virgen de los mártires mexicanos". No faltaron protestantes y judíos para solidarizarse con los católicos mexicanos. Todo esto tuvo un efecto retroactivo sobre la Iglesia mexicana y los fieles, que comprobaron así que "como México no hay dos." Algún día, un papa polaco compararía la virgen negra de Czestochowa con la morena del Tepeyac y diría de México: Semper fidelis.

\section{Los arreglos de 1929 y la paz definitiva de 1938:}

la mediación internacional

La literatura existente sobre la gestación de los arreglos es inmensa. Baste recordar que varios países ofrecieron sus "buenos oficios" desde 1926, como el Perú, y pusieron diplomacia y clero a trabajar pacientemente para mediar entre las partes en conflicto que no podían tratar cara a cara. Los Estados Unidos, con el famoso embajador Dwight W. Morrow, el P. John F. Burke, el jesuita Edward Walsh, el periodista Walter Lippmann; Francia, con sus embajadores en México, Washington (Paul Claudel), el Vaticano (Louis de Fontenay) y el famoso informe de Ernest Lagarde; Chile con 
Miguel Cruchaga y Tocornal en México -tan importante, en la última etapa, si no es que más que D. W. Morrow- y su embajador en Roma; las nunciaturas respectivas del Vaticano en cada uno de esos países, y la delegación apostólica en el caso de Washington.

Hasta la Italia fascista tuvo una influencia, si no directa, decisiva: en febrero de 1929, menos de cuatro meses antes de los arreglos, Mussolini celebró con el Vaticano los famosos "acuerdos de Letrán", que pusieron fin a una "cuestión romana" pendiente desde 1870. En abril del mismo año, il Duce declaraba que "la religión es invencible" y que quien rompe la unidad religiosa nacional "comete un crimen contra el pueblo." Ese cambio de línea por parte del régimen fascista fortaleció la línea conciliadora en el Vaticano y la esperanza de que, tarde o temprano, el radicalismo del régimen mexicano se ablandaría.

Para EEUU, de 1914 a 1938, la cuestión religiosa en México tuvo su importancia; desde Wilson hasta Roosevelt, todos los presidentes la sufrieron. Bien lo dijo Walter Lippmann, editorialista del New York Times, el 29 de diciembre de 1927: "Los estadounidenses no podemos quedar indiferentes frente a la cuestión. Mientras no haya paz entre la Iglesia y el Estado en México, no habrá paz entre México y los Estados Unidos". Por eso, los Estados Unidos tuvieron un papel decisivo y positivo, aunque poco publicitado, en el lento y paulatino final del conflicto, entre 1935 y 1938, cuando Franklin D. Roosevelt, presionado sin tregua por el lobby católico de su país, apremió a su vez al flamante gobierno del general Lázaro Cárdenas. ${ }^{6}$

A lo largo de estos veinticuatro años, los católicos mexicanos descubrieron con sorpresa, incrédula al principio, la existencia, el dinamismo, la solidaridad de la catolicidad estadounidense.

\section{Después del conflicto y hasta el Concilio Vaticano II}

\section{"La Iglesia era un roble". 1939-1959}

Escribe don Luis González:

Ni el leñador líder, ni el leñador intelectual, ni el leñador político lograron entonces que sus hachas penetraran mayormente en el tronco eclesiástico. Aunque el gobierno redujo [...] el cura siguió contemplando a su pueblo desde las torres parroquiales y haciéndole a la rienda desde el confesionario y el púlpito.7

\begin{tabular}{l|l}
6 & Meyer, La cruzada. \\
7 & González y González, Historia de la revolución mexicana, pp. 62 y ss.
\end{tabular} 
Finalizado el conflicto religioso, simbólicamente, el 18 de marzo de 1938, a la hora de la nacionalización del petróleo, ${ }^{8}$ la Iglesia y los católicos reaccionaron frente a la guerra civil española (y la llegada de los refugiados republicanos), al fascismo y nazismo, luego a la guerra mundial. En México se supo inmediatamente, con lujo de detalles, la matanza inicial de miles de sacerdotes, varios obispos, monjas, el incendio de templos y conventos en julio y agosto de 1936. El México católico vibró a la lectura de la Pastoral colectiva española redactada por el cardenal Gomá (1ํ de julio de 1937). Luis González cuenta en Pueblo en vilo cómo su pueblo de San José, cristero hasta el tuétano, deseaba la victoria nacionalista. En ese ambiente nacen la Unión Nacional Sinarquista y el Partido Acción Nacional: en España, en 1931, unos católicos habían fundado "Acción Nacional", luego llamada "Popular", antecedente de la Confederación Española de Derechas Autónomas (CEDA, 1935).

La guerra de España, ${ }^{9}$ el apogeo de los fascismos, su impacto en toda América, los triunfos militares alemanes, el reparto de Polonia y de los países bálticos entre Hitler y Stalin, la agresión soviética contra Finlandia, todo llevó al presidente Cárdenas a guiar el aterrizaje modernizante de la Revolución mexicana con la candidatura del general (católico) Manuel Ávila Camacho. En ese contexto mundial, la Iglesia se sumó a la política de unidad nacional a la hora de los peligros externos y de la guerra. No estuvo de más la nueva alianza entre Estado e Iglesia para convencer a los mexicanos de rebajar un poco su germanofilia y antiyanquismo.

Durante la guerra, les costó algo de trabajo a los católicos entender la alianza entre las democracias y la Unión Soviética; ciertamente el papa había condenado el nacional-socialismo en su encíclica Mit brennender Sorge, pero en los mismos días, en Divini redemptoris, había declarado que el comunismo era "intrínsecamente perverso". Ahora resultaba que México entraba en guerra contra Alemania, jal lado de los EEUU y de la URSS! ${ }^{10}$ El 30 de mayo de 1942, tres días antes de que el presidente declarara el "estado de guerra", el arzobispo de México, don Luis María Martínez, había publicado una carta de apoyo al gobierno para orientar la opinión a favor de los Aliados. El 8 de noviembre de 1943, don Luis María Martínez explicó en la prensa nacional que

10
Comité Ejecutivo Episcopal, "Los católicos". Junco, El difícil paraíso.

No creo que se haya estudiado la recepción de esas encíclicas de 1937 en el seno de la Iglesia mexicana. 
en estos momentos en que México toma parte en una guerra trascendental que señala un nuevo rumbo a la historia humana [...] la solemnidad de esta hora exige que toda nuestra energía y nuestro entusiasmo se concentren en robustecer esa unidad nacional que tanto ha recomendado el señor Presidente de la República.

Los sexenios siguientes no cambiaron nada a esta situación; la novedad era internacional, con la desaparición de fascismos y nazismo, con el principio de la guerra fría y el nuevo estatuto del comunismo como enemigo único. El anticomunismo de la Iglesia universal, y de la mexicana como parte de ella, era una realidad persistente. La persecución de todos los cristianos en la URSS y ahora en Europa del Este fortaleció un sentimiento que no necesitaba de estímulo. El papa denunció cien veces el comunismo, los católicos mexicanos sufrieron con los cardenales encarcelados, el polaco y el húngaro, sus nuevos héroes.

\section{Castrismo y libro de texto}

La revolución cubana, en tales condiciones, tan pronto como Fidel Castro se afirmaba marxista y leninista desde siempre, tenía que movilizar a muchos católicos; la ofensiva contra una Iglesia hermana, que había ayudado mucho a la mexicana entre 1914 y 1938, levantó gran emoción no solamente por la llegada de sacerdotes y monjas exiliados de la isla, sino por la coincidencia cronológica entre el castrismo y un nuevo episodio de la guerra escolar, el del "libro de texto único". Dichos libros fueron preparados para la escuela primaria por la Secretaría de Educación a partir de febrero de 1959.

La historia de la batalla es bien conocida y va del verano de 1961 hasta abril de 1963. Se dio bajo el lema de “¡Cristianismo sí, comunismo no!", y Fidel Castro aparecía como un nuevo Plutarco Elías Calles, peor que Calles, porque amenazaba a todo el continente. Se supo que los insurgentes cubanos del Escambray morían fusilados al grito de "iViva Cristo Rey!". El miedo era compartido por todas las iglesias de América Latina, precisamente cuando se multiplicaban los contactos y se descubría la solidaridad continental en las asambleas del Consejo Episcopal Latinoamericano (CELAM). El P. Pedro Velásquez, del Secretariado Social de la Iglesia mexicana, presentó un informe al episcopado sobre la situación en la isla, antes de publicar, con A. Michel, el libro La lucha comunista contra la religión, el testimonio de la Iglesia del silencio.

Contra el libro de texto único hubo dieciocho meses de marchas, enormes manifestaciones, peticiones, cartas pastorales y folletos, campañas 
de oración. Al final el Estado y la Iglesia fueron capaces de calmar el juego y la psicosis anticomunista desapareció, al grado de que la jerarquía empezó a atacar las sociedades secretas de la ultraderecha católica.

\section{La fase preconciliar}

En 1955 Roma transformó el Comité Ejecutivo Episcopal de 1937 en Conferencia Episcopal y el papa creó el CELAM, destinado a multiplicar efectivamente las relaciones entre las iglesias del subcontinente; se reunió por primera vez en Río de Janeiro en 1955. En 1959, el papa Juan XXIII dio la sorpresa al convocar un concilio en Roma. Dos iniciativas romanas que fueron prolongadas por la creación, en 1960, de la Confederación Latinoamericana de Religiosos (CLAR) y Conferencia de Institutos Religiosos de México (CIRM), dos organismos llamados a desempeñar un gran papel en los cambios religiosos del país y del continente.

La CLAR reunía a las conferencias nacionales de religiosos de veintiún países y contaba, en 1960, con 130000 monjas, 20000 hermanos y 25000 sacerdotes; la primera reunión tuvo lugar en Lima en 1960, la segunda en Río en 1963 y la tercera en México en 1966.

Cuando Juan XXIII lanzó el lema del aggiornamento de la Iglesia, en México el asombro fue mayúsculo, si bien se dio la bienvenida a la convocatoria conciliar. ${ }^{11}$ Empezaba la batalla del libro de texto y el anticomunismo ocupaba los espíritus, de modo que las encíclicas Mater et magistra (1961) y Pacem in Terris (1963), que proponían cambios en las relaciones entre poseedores y desposeídos y cambios en la Iglesia para luchar por la justicia, no tuvieron tanto eco como en Europa. Tampoco fueron tan leídos teólogos como Yves Marie Congar, O.P., ${ }^{12}$ y M.D. Chenu, O.P., cuando propusieron que la Iglesia se convirtiera en la pobre servidora de la justicia en el mundo. El Concilio iba a cambiar esto.

\section{El Concilio y después}

\section{La transformación conciliar}

De nueva cuenta, una intervención pontificia revirtió la corriente dominante tanto en el seno de la Iglesia mexicana como de la Iglesia universal al provocar una sorprendente revolución desde arriba para reformar la institución. Participaron activamente en el Concilio mexicanos como el

\footnotetext{
11 Pérez Azuela, "El próximo Concilio", p. 40.

12 Jalones para una teología del laicado.
} 
arzobispo de México, Miguel Darío Miranda, y el obispo de Cuernavaca, Sergio Méndez Arceo; ${ }^{13}$ muchos obispos regresaron transformados, como Samuel Ruiz, arzobispo de Chiapas..$^{14}$ Fue inesperada y notable la participación de dos auditores laicos mexicanos, el matrimonio Álvarez Icaza, presidentes del Secretariado para América Latina del entonces pujante Movimiento Familiar Cristiano. En 1964 José Álvarez Icaza recibió el encargo del episcopado de crear el Centro Nacional de Comunicación Social (CENCOS) para difundir la pastoral social en la línea conciliar. El jesuita Enrique Maza escribía: "cada pobre, con su matiz propio de miseria, es recuerdo y como sacramento del Gran Pobre, Jesucristo, quien siendo rico se hizo pobre, para hacerlos ricos con su pobreza". ${ }^{15}$

Los religiosos y los laicos que habían estudiado en Europa y conocían las corrientes bíblicas y de renovación litúrgica empujaban hacia adelante el movimiento conciliar que, al principio, se topaba con incomprensión y miedo. Entre las iniciativas notables destaca la edición mexicana de las Informations Catholiques Internacionales, que cubría semana a semana la crónica del Concilio y despertaba a los laicos. Gabriel Zaid, en la línea de Économie et Humanisme del P. Lebret, ${ }^{16}$ participó en este proyecto y siguió de cerca la trayectoria de Iván Illich (1929-2002).

Sacerdote con rango de monseñor, diplomático de altos vuelos, consejero de dos cardenales en Estados Unidos, Iván Illich dejó la Universidad Católica de Puerto Rico para fundar, en 1961, en Cuernavaca, sede del obispo Méndez Arceo, el Centro de Información y Documentación (CIDOC), que no tardó en ser conocido en toda América y en el mundo. Los folletos y cuadernos del CIDOC, publicados a una velocidad impresionante, se hicieron famosos por la participación de personalidades como Peter Berger, Paulo Freire, Erich Fromm, Paul Goodman, Francisco Juliao. En Cuernavaca estaban también el obispo don Sergio, denunciado por la derecha como "el obispo rojo" amigo de Castro, y el benedictino Lemercier, denunciado por su práctica del psicoanálisis en el marco conventual. Dos extranjeros y un mexicano cuyas imágenes se confundían para la gente de fuera, especialmente para los enemigos del movimiento. No sorprende al historiador que en 1967 el CIDOC haya sido censurado por la Iglesia. Illich cortó por lo sano y, en palabras suyas,

13

14

15

16

ñía de François Perroux.

Meyer, Samuel Ruiz.

López Bucio, Don Sergio Méndez Arceo.

Maza, Christus, pp. 686-688, citando a San Pablo, II Corintios.8.9.

"Economía y Humanismo" movimiento fundado en 1941 por el Padre Lebret en compa- 
le dije entonces a la Iglesia, "hiciste un escándalo de mí, nunca más volveré a verme envuelto en ninguna acción que la Iglesia católica romana considere propia de un sacerdote. Rechazo mis privilegios y cualquier deber dentro del sistema clerical". ${ }^{17}$

\section{Escribe Soledad Loaeza:}

Quizá una de las consecuencias del Concilio de mayor alcance para la Iglesia en América Latina haya sido su invitación a una mayor apertura intelectual a las disciplinas seculares, en particular a las ciencias sociales, como fuente legítima de conocimiento del mundo.

Iván Illich lo había anticipado.

Así, la doctrina social cristiana dejó de ser la única fuente de inspiración de los católicos comprometidos. El desplazamiento de la doctrina se fundó también en la propuesta de los documentos conciliares de que se reconociera la validez de los valores temporales... ${ }^{18}$

El Concilio planteó el concepto de la Iglesia como "pueblo de Dios" sin adivinar que iba a ser uno de los elementos constitutivos de la teología de la liberación y piedra de toque del progresismo católico: del "compromiso con los pobres" se pasó al de una Iglesia para los pobres y, finalmente, al de "Iglesia popular". El concepto tradicional de "acción pastoral" como difusión de la enseñanza religiosa y asistencia a los necesitados se transformó en testimonio, solidaridad, denuncia y, finalmente, acción contra la explotación y la opresión. Lo cual llevó al encuentro con el comunismo y, para algunos, a la lucha armada como opción a favor de los pobres.

Antes de tratar de la teología de la liberación y de sus avatares, hay que hablar de una revolución silenciosa que apenas empezaba en México, y que tenía ya una dimensión continental.

\section{Las Iglesias evangélicas}

Si el Concilio llegó como un relámpago en un cielo azul, la expansión del protestantismo se estaba dando en forma discreta, geográficamente periférica, de modo que al principio, en los años cincuenta y sesenta, casi pasó

17

18 Ivan Illich entrevistado por David Cayley, www.ivanillich.org/Principal. "Iván Illich en México. Conversación de Jean Robert con Gustavo Esteva", 2000.

Loaeza, La restauración, p. 26. 
desapercibida y en todos los casos fue subestimada. No fueron las Iglesias históricas, sino la cristiandad evangélica, considerada en Estados Unidos como el cuarto revival, la que creció y sigue creciendo más rápido en América Latina, África y Asia y es capaz de implantarse hasta en tierra del Islam.

Así, entre 1950 y 2000 la Iglesia católica, sin dejar de ser mayoritaria, perdió su histórico monopolio de ser la única Iglesia cristiana. Según los censos, la población que se declara católica pasa de 95\% en 1950 a 88\% en 2000 y $86 \%$ en 2010. En 2010, entre la población de 15 años y más, hay 92924489 registrados como católicos y 8386207 como "Protestante/ pentecostal/evangélico"; el desglose da para la categoría "protestante histórica o reformada": 820 744, y "Pentecostal/evangélica": 7565463. Hay que contar además 661878 adventistas, 314932 mormones y 1561 086 testigos de Jehová. ${ }^{19}$ En total, quienes profesan una religión distinta a la mayoritaria o no tienen una creencia son casi quince por ciento de la población. La Iglesia católica sigue siendo un roble, pero varios arbolitos la rodean ya. Mientras la católica tiene 21000 ministros de culto, las otras confesiones alinean ¡68 000!

Es en el Sureste del país donde el fenómeno tiene más fuerza. Por ejemplo, en el estado de Chiapas la población no católica suma un tercio del total, y en varios municipios el catolicismo ha dejado de ser religión mayoritaria. ${ }^{20}$ En Tabasco, Campeche y Quintana Roo, la cuarta parte de los habitantes no son católicos.

La afirmación de ese neoprotestantismo había empezado cincuenta años antes en el Cono Sur, antes de llegar a Brasil y Centroamérica. Se estima que los protestantes, que no llegaban a cien mil a principios del siglo Xx en América Latina, pasaban ya de 45000000 en 1990. Entre 1960 y 1985 el número de evangélicos se duplicó en Chile, Paraguay, Venezuela y se triplicó en Argentina, Nicaragua, República Dominicana; al mismo tiempo se multiplicó por cuatro en Brasil y Puerto Rico, por cinco en el Perú, Bolivia, Costa Rica y El Salvador; por seis en Ecuador, Colombia y Honduras. Guatemala rompe récord con un aumento de siete veces. Precisamente desde Guatemala la expansión protestante pasa a México, lo que contribuye a estimular el dinamismo de monseñor Samuel Ruiz.

La ola "está marcada por un énfasis anticatólico y proselitista, sostenido por Estados Unidos; muy vinculado al credo americano y a la ideología político-religiosa del destino manifiesto". ${ }^{21}$ Ese nuevo modelo

\footnotetext{
19 INEGi, Censo General de Población y Vivienda 2010 y Panorama de las religiones en México, 2010.

20 Meyer, Samuel Ruiz, pp. 51-59.

21 Guzmán M. Carriquiry Lecour, Una scommessa.
} 
religioso es muy diferente del de la Iglesia católica y de las iglesias protestantes históricas. No presenta una sociedad global y universal como la Iglesia católica, sino un mundo religioso fluido, con iniciativas que pueden ser exitosas. Andrei Chestnust diagnostica correctamente: "La Iglesia católica ha elegido a los pobres, pero los pobres han elegido el pentecostalismo". ${ }^{22}$ Es importante resaltar que, según el censo de 2010, casi $40 \%$ de los cristianos no católicos vive en zonas de alta y muy alta marginación, por encima de los católicos (28\% en esta situación). En el sureste del país convergen los grados más altos de pobreza y la mayor presencia porcentual de evangélicos. En 1964, en su seminario parisino de la École des Hautes Études, Pierre Chaunu, con mucha visión, anunciaba un gran porvenir para el fenómeno y nos explicaba que se trataba de una nueva versión de las tesis de Max Weber sobre la ética protestante y el espíritu del capitalismo: esa Iglesia de los pobres ofrece la esperanza de una movilidad social ascendente, especialmente para las mujeres, las cuales luego convierten a su pareja: la conversión significa la adopción de una ética rigurosa que implica la renuncia al alcohol, a las fiestas y al sistema de cargos de las comunidades tradicionales. Ese cambio radical de vida permite una modesta "acumulación primitiva" de capital.

Se trata de un fenómeno que se da a escala mundial y refleja la inmersión de México en la aldea global. Las migraciones internas e internacionales contribuyen al movimiento.

La migración es uno de los factores explicativos del cambio religioso, sea migración del campo hacía la ciudad, adentro del país o allende de la frontera, sea migración rural-rural, en búsqueda de trabajo, otra vez en México o en los Estados Unidos. En todos los casos se da el alejamiento de los controles comunitarios y el contacto con la pluralidad religiosa, en una situación de vulnerabilidad ligada con la condición migratoria. En el caso de la migración internacional no hay que pensar que tiene un impacto en reversa, provocando el cambio religioso en el punto de partida. Puede parecer sorprendente, pero los estados donde el evangelismo ha progresado de manera más rápida no han tenido una participación importante en las migraciones: por ejemplo, apenas empieza el éxodo rural en Chiapas. Los estados con mayor y más antigua tradición migratoria hacia Estados Unidos desde los años 1880-1890, como Jalisco y Michoacán, figuran entre los que mantienen un elevado porcentaje de catolicismo.$^{23} \mathrm{No}$

22

23

Citado por R. Gritti, La política, p. 153.

El Panorama de las religiones en México, 2010, publicado por el INEGI, da cifras detalladas estado por estado. 
me atrevo a decir que existe una relación casi inversa entre la migración internacional y la adscripción religiosa, pero casi.

Sin embargo, entre los migrantes definitivos la situación es diferente. En el Atlas de la diversidad religiosa en México, coordinado por Renée de la Torre y Cristina Gutiérrez Zúñiga, se demuestra que cruzar la frontera no lleva mecánicamente a cambiar de confesión; citan el estudio Hispanic Churches in American Public Life, que encuentra que $70 \%$ de los "latinos" que viven en Estados Unidos se consideran católicos. Sin embargo, este porcentaje varía entre quienes nacieron y crecieron en otro país, sus hijos y nietos: en la generación que emigró, el catolicismo mantiene cuando menos $74 \%$, pero en la de sus hijos desciende a 72\%, y llega aproximadamente a $62 \%$ para la tercera generación. Simultáneamente, la adscripción al protestantismo pasa de menos de 15\% en la generación migrante a $20 \%$ en la segunda y casi $29 \%$ en la tercera. ${ }^{24}$

En cuanto a la migración interna, si bien puede promover el cambio de adscripción, existe también la relación inversa, a saber, como en casos muy estudiados de Chiapas, que es el cambio religioso que provoca la migración bajo la forma de expulsión: las comunidades de origen no aceptan la diversidad religiosa y destierran tanto a los evangélicos como a los "nuevos católicos", los que siguen la pastoral lanzada por el arzobispo Samuel Ruiz a partir del Concilio Vaticano II.

Para la Iglesia católica, el neoprotestantismo fue y es un reto que la invita a ser menos segura de sí misma y más carismática. El pesimista puede decir, como el cardenal brasileño Neves, que "la primavera de las sectas podría llevar al invierno de la Iglesia católica"; el optimista, como el futuro Benedicto XVI, piensa en 1984 que "su expansión demuestra los vacíos y carencias de nuestro anuncio y de nuestra praxis." 25

El fenómeno es continental: según datos del Pew Research Center y del World Religión Data Base, en 2014 19\% de los latinoamericanos ya profesaban el cristianismo bajo una de las múltiples formas protestantes.

\section{La(s) teología(s) de la liberación}

Desde 1982 he escrito muchísimo sobre el tema, así que trataré de ser breve. En 1969, el Informe Rockefeller y el documento de la Rand Corporation, preparados para el presidente Richard Nixon, dicen:

24

25

Riccardi, Juan Pablo II, p. 330. Ver también "Il fenómeno delle sètte o nuovi fenomeni religiosi", en Enchiridion Vaticanum. Documenti ufficiali della Santa Sede, Bolonia, 1989, pp. 252-285, citado por Ricardi, Juan Pablo II, p. 310. 
La Iglesia católica en América Latina está en una gran efervescencia como probablemente nunca estuvo antes [...]. La Iglesia, con un profundo idealismo, pero como resultado de ello en algunos casos vulnerable a la penetración subversiva, está pronta a llevar a cabo una revolución, si fuese necesario, para poner fin a la injusticia, pero sin claridad en cuanto a la naturaleza última de la revolución misma o al sistema gubernamental mediante el cual se puede realizar la justicia que busca. ${ }^{26}$

Diez años más tarde, en 1979, el presidente Jimmy Carter ordenó a la CIA seguir de cerca el movimiento católico en América Latina, para evitar amargas sorpresas contra los Estados Unidos del tipo de la que había sufrido en Irán en febrero.

Desde el Concilio, el catolicismo había intensificado su compromiso con los pobres, la Iglesia asumía posiciones críticas contra las dictaduras y la desigualdad social, mientras que se difundían la teología de la liberación y el movimiento de las comunidades de base. El resultado inmediato fue la represión y "el apoyo a una contrarrevolución religiosa a través del neoprotestantismo, como dique al compromiso social de la Iglesia y la opción socialista de los católicos" ${ }^{27}$

En México, órdenes religiosas como la Compañía de Jesús se encontraban en la punta del movimiento ${ }^{28}$, en compañía de sacerdotes diocesanos y de jóvenes católicos, algunos de los cuales llegaron a tomar las armas, sea en el país, sea en Centroamérica. La segunda Conferencia General de los obispos latinoamericanos, en Medellín, en 1968, desencadenó la ofensiva del radicalismo católico. La revolución nicaragüense, que triunfó en 1979, llevó al poder a más de cuatro religiosos, algo que preocupó sobremanera a los EEUU; las guerras civiles de El Salvador y Honduras, los brotes guerrilleros mexicanos, incluso el de 1994 en Chiapas, llevaban el sello de la teología de la liberación. En 1971 el teólogo peruano Gustavo Gutiérrez publicó su Teología de la Liberación: perspectivas, afirmando que después de Medellín el término "desarrollo" era obsoleto y debía dejar lugar al concepto de "liberación".

Tal radicalización tuvo por resultado la división de los católicos, tanto en México como en todo el continente, en tres corrientes: la progresista radical, la conservadora y la de los que se negaban a mezclar política y

26 Del Informe Rockefeller, citado por Miguel Concha, "El cristianismo latinoamericano", Unomásuno, 18 de enero de 1981, p. 8.

27

28 Meyer, "Los jesuitas mexicanos", pp. 455- 477. 
religión, si bien asumían su responsabilidad social. Fue cuando el nuevo papa llegó a México, en 1979.

\section{Juan Pablo II}

Una vez más, el impulso vino de Roma. En 1979, como en sus cinco visitas a México (la última en 2002), el papa recibió una cálida acogida que fue cada vez in crescendo y dio a la Iglesia mexicana una renovada seguridad en sí misma. A fines de enero y principios de febrero de 1979, la tercera Conferencia Plenaria del CELAM (se celebra una cada diez años) fue presidida en Puebla por el papa polaco, quien frustró las expectativas de los liberacionistas: desde su discurso inaugural, desaprobó la teología de la liberación y la ingenuidad de los que creían posible bautizar al marxismo y a la lucha de clases. Rechazó el concepto de "Iglesia popular" y los "radicalismos sociopolíticos". "Parece que en Puebla monseñor Helder Cámara le dijo: Santidad, recuerde que la Iglesia católica no es una Polonia gigante." ${ }^{29}$ Sin embargo, Juan Pablo, consciente de la grave cuestión representada por los regímenes dictatoriales y la consecuente atracción del marxismo para muchos católicos, encontraba una semejanza entre su Polonia natal y América Latina. En 1975 la había descrito a los obispos polacos: "una tradición de sociedad católica homogénea, con cierto carácter popular, combinada con el problema de la justicia social y la batalla por los derechos humanos." Ahora venía a restaurar una homogeneidad perdida, puesto que para él la unidad era una prioridad absoluta, unidad entre los obispos, unidad entre los fieles.

En 1983, Juan Pablo enfrentó a los sacerdotes del régimen revolucionario sandinista de Nicaragua, en particular al jesuita ministro de la Cultura, Ernesto Cardenal. Convencido de los riesgos de la teología de la liberación cuando se acerca demasiado al marxismo, le encargó en 1984 a su amigo Joseph Ratzinger una Instrucción sobre algunos aspectos de la "teología de la liberación". El futuro Benedicto XVI escribió: "Si se sacraliza la revolución, mezclando a Dios y a Cristo con las ideologías, se produce un fanatismo entusiasta que puede llevar a las peores injusticias y opresiones." Se trataba de limitar la influencia del marxismo sobre la teología, a la vez que de afirmar el valor de la liberación: un equilibrio difícil de encontrar. A diferencia de lo que pasó en Brasil, los católicos mexicanos recibieron tranquilamente las instrucciones del "inquisidor"; luego, la caída del Muro de Berlín puso fin a la controversia. En la encíclica Centesimus annus de 1991, el papa pudo escribir:

29 Riccardi, Juan Pablo II, p. 311. 
En el pasado reciente, el deseo sincero de ponerse de parte de los oprimidos y de no quedarse fuera del curso de la historia ha inducido a muchos creyentes a buscar por diversos caminos un compromiso imposible entre marxismo y cristianismo. El tiempo presente, a la vez que ha superado todo lo que había de caduco en estos intentos, lleva a reafirmar lo positivo de una auténtica teología de la liberación humana integral. ${ }^{30}$

\section{Conclusiones}

En forma de invitación a situarse en el marco de las relaciones internacionales para entender al Vaticano y la Iglesia católica mexicana, me limitaré a enumerar una serie de puntos que merecen un tratamiento profundo.

a) Se abre a finales de los años 1980, a iniciativa del presidente Carlos Salinas de Gortari, un periodo de intensos intercambios entre el gobierno mexicano, el Vaticano y la Iglesia mexicana. Baste mencionar la reforma de la Constitución que pone fin a los artículos criticados por la Iglesia desde 1917 y el establecimiento de relaciones diplomáticas entre la Santa Sede y México. ${ }^{31}$ Soledad Loaeza observa, a la distancia, que "en México, la Iglesia difícilmente hubiera emprendido la lucha por los derechos humanos y un ejercicio tan claro de distanciamiento de las autoridades gubernamentales si no hubiera recibido el impulso del Papa". ${ }^{32}$

b) En otro nivel, tenemos al arzobispo de Chiapas, Samuel Ruiz, quien convoca a sacerdotes extranjeros para ayudarlo a renovar radicalmente su pastoral: canadienses, estadounidenses, belgas como el jesuita Jan de Vos, franceses como André Aubry o el P. Chanteau, españoles, etc., que forman el 10\% del clero de la diócesis de San Cristóbal.

c) En sentido inverso, México exporta sacerdotes y monjas al mundo entero, y la presencia masiva de católicos mexicanos en los Estados Unidos tiene un impacto digno de tomarse en cuenta sobre la Iglesia estadounidense: son los nuevos irlandeses.

d) El peso de la Iglesia mexicana en América Latina se hace notar, por ejemplo, con la elección del obispo de Tapachula, Felipe Arizmendi, como secretario general del CELAM (1995-1999), luego del obispo de Texcoco, Carlos Aguiar Retes, primero como secretario general (1999-2003), luego como primer vicepresidente de dicha Conferencia (2003-2007).

30 Riccardi, Juan Pablo II, p. 314. Véase Ceci, La teologia della liberazione in America Latina. L'opera di Gustavo Gutiérrez, y Scatena, La teologia della liberazione in America Latina.

31

32 Loaeza, La restauración, p. 169. 
e) Los mexicanos Legionarios de Cristo, fundados por el tristemente famoso P. Marcial Maciel, un hombre proteico que supo ganarse la confianza absoluta de muchos (desde el hombre más rico del mundo, Carlos Slim, hasta Juan Pablo II), están presentes en otras partes del mundo. Para bien y para mal son "la única multinacional mexicana en materia religiosa", según la definición de Dionisio Garza Medina, empresario de Monterrey. ${ }^{33}$

f) Los católicos han sido muy sensibles, desde el pontificado de Pío IX en la segunda mitad del siglo XIX, a la autoridad del papa, y por lo menos desde Pío XII, a la persona misma del papa. Inútil recordar el entusiasmo despertado por las visitas de Juan Pablo II a partir de 1979. Es algo que permite a los protestantes hablar de "papolatría". Hace dos años que un jesuita argentino, Jorge Bergoglio, ocupa la silla de Pedro con el nombre de Francisco. Su "estilo personal de gobernar", su carga contra la Curia romana, cuando denunció las quince "enfermedades curiales... alzheimer espiritual... esquizofrenia existencial", entre otras, su apoyo a la diplomacia discreta del Vaticano para descongelar las relaciones entre La Habana y Washington, todo parece anunciar un pontificado importante. Ahora bien: el papa Francisco está invitado a visitar México. Si las autoridades creen que van a poder capitalizar su visita sin costo alguno, se equivocan mucho, como lo ha demostrado en febrero de 2014 su famosa advertencia (privada) a un amigo argentino: "Ojalá estemos a tiempo de evitar la mexicanización. Estuve hablando con los obispos mexicanos y la cosa es de terror". Así expresaba su preocupación por el avance del narcotráfico en Argentina. Un papa que no tiene pelos en la lengua, que sacude a la cúpula de la Iglesia, bien podría despertar, dinamizar a los católicos mexicanos y a sus eclesiásticos. La reacción hipersensible del gobierno mexicano no se hizo esperar, aunque sin llegar al incidente diplomático. La lección que todos deberían sacar es que no habrá manera de censurar al papa y que la Iglesia mexicana deberá imitarlo en su aggiornamento.

\section{Bibliografía}

Carriquiry Lecour, Guzmán M.

Una scommessa per l'America Latina. Memoria e destino storico di un continente, Florencia, Le Lettere, 2003.

Ceci, Lucía

La teologia della liberazione in America Latina. L'opera di Gustavo Gutiérrez, Milán, F. Angeli, 1999.

33 | José de Córdoba, "Wealthy Kingdom...", The Wall Street Journal, 23 de enero de 2006. 
Codevilla, Giovanni

Chiesa e Impero in Russia. Dalla Rus' di Kiev alla Federazione Russa, Lucca, Jaca Book, 2011.

Comité Ejecutivo Episcopal

"Los católicos mexicanos y la deuda petrolera", declaración del 1ํ de mayo, México, Christus, núm. 31, junio de 1938.

Congar, Yves Marie

Jalones para una teología del laicado, Barcelona, Estela, 1963.

Cordoba, José de

"Wealthy Kingdom...", The Wall Street Journal, 23 de enero de 2006.

González y González, Luis

Historia de la Revolución mexicana, tomo XIV, México, El Colegio de México, 1978.

Gonzalez, Philippe

Que ton Règne vienne. Des évangéliques tentés par la conquête du pouvoir, Ginebra, Labor et Fides, 2014.

González Schmall, Raúl

Memorias del Primer Congreso Internacional sobre iglesias, estado laico y sociedad, México, Konrad Adenauer Stiftung, Instituto Mexicano de Doctrina Social Cristiana, Conferencia Episcopal, 2006.

Gritti, Roberto

La politica del sacro. Laicità, religiones, fondamentalismi, nel mondo globalizzato, Milán, Guerini Studio, 2004.

Gutiérrez, Gustavo

Teología de la Liberación: perspectivas, Salamanca, Ediciones Sígueme, 1975.

Hernández Hernández, Alberto

Frontera norte de México. Escenarios de diversidad religiosa, Zamora, El Colegio de la Frontera Norte, El Colegio de Michoacán, 2013.

Instituto Mexicano de Doctrina Social Cristiana, IPSos, Creer en México. Estudio de opinión, 2014, www.encuestacreerenmexico.mx y los doce artículos que analizan los resultados en Este País, del número 277 de mayo de 2014 al 289 de abril 2015.

Instituto Nacional de Estadística Geografía e Informatica, Diversidad religiosa en México, México, Instituto Nacional de Estadística Geografía e Informatica, 2005.

Instituto Nacional de Estadística Geografía e Informatica, Panorama de las religiones en México, 2010, México, Instituto Nacional de Estadística Geografía e Informatica, 2011.

Junco, Alfonso

El difícil paraíso, México, Helios, 1940. 
Junco, Alfonso

México y los refugiados. Las Cortes de paja y el corte de caja, México, Jus, 1959.

Krasnov-Levitin, A. y V. Shavrov

Ocherki po istorii russkoi tserkovnoi smuty, (Ensayo sobre la historia del tiempo de los disturbios de la Iglesia rusa), Zürich, Institut Glaube in der Welt 2, 1977.

Loaeza, Soledad

"La Iglesia católica mexicana y las relaciones internacionales", Foro Internacional, núm. 126, octubre-diciembre de 1991.

Loaeza, Soledad

La restauración de la Iglesia en la transición mexicana, México, El Colegio de México, 2013.

López Bucio, Baltasar

Don Sergio Méndez Arceo, México, Secretariado Social Mexicano, 1993.

Maza, Enrique

Christus, México, II semestre de 1963.

Meyer, Jean

"Los jesuitas mexicanos en el siglo xx: historia de la disidencia", Roderic Ai Camp (ed.), Los intelectuales y el poder en México, México, El Colegio de México, Universidad de California, Los Angeles, 1991.

Meyer, Jean

Historia de los cristianos de América Latina, siglos XIX y XX, México, Jus, 1999.

Meyer, Jean

Samuel Ruiz en San Cristóbal, México, Tusquets, 2000.

Meyer, Jean

"Dos revoluciones, un triángulo. Moscú, el Vaticano y México, 19221929", Historias, núm. 52, México, Instituto Nacional de Antropología e Historia, septiembre-diciembre de 2002, pp. 89-95.

Meyer, Jean

"La Iglesia católica en México, 1929-1965", Historias, núm. 70, mayoagosto de 2008, México, Instituto Nacional de Antropología e Historia, pp. 55-84.

Meyer, Jean

La cruzada por México, los católicos de Estados Unidos y la cuestión religiosa en México, México, Tusquets, 2008.

Meyer, Jean

"La crisis de México y las Iglesias cristianas", en José Ramón Cossío y Enrique Florescano, La perspectiva mexicana en el siglo XXI, México, Fondo de Cultura Económica, 2012. 
Meyer, Jean (coord.)

Las naciones frente al conflicto religioso en México, 1926-1929, México, Tusquets, Centro de Investigación y Docencia Económicas, 2010.

Michel, A. y Pedro Velázquez

La lucha comunista contra la religión, el testimonio de la Iglesia del silencio, México, Secretariado Social Mexicano, 1960.

Pérez Azuela, Rubén

"El próximo Concilio Ecuménico", Revista Signo del Reino de Dios, núm. 1, México, 1960.

Pérez- Rayón, Nora

Estado, Iglesia católica y anticlericalismo en México. La primera visita de Juan Pablo II en la prensa de opinión, México, Universidad Nacional Autónoma de México, 2013.

Riccardi, Andrea

Juan Pablo II. La biografía, San Pablo, Bogotá, 2011.

Robert, Jean y Gustavo Esteva

"Ivan Illich en México", Christus, núm. 28, México, 2000.

Reyes, Aurelio de los

El nacimiento de ¡Que viva México!, México, Universidad Nacional Autónoma de México, 2006.

Savarino, Francisco y Andrea Mutolo (coord.)

El anticlericalismo en México, México, Instituto Tecnológico y de Estudios Superiores de Monterrey, Cámara de Diputados, Miguel Ángel Porrúa, 2008.

Scatena, Silvia

La teologia della liberazione in America Latina, Roma, Carroci, 2008.

Torre, Renée de la y Cristina Gutiérrez Zuñiga (coord.)

Atlas de la diversidad religiosa en México, 1950-2008, México, El Colegio de Jalisco, El Colegio de la Frontera Norte, El Colegio de Michoacán, Centro de Investigaciones y Estudios Superiores en Antropología Social, Universidad de Quintana Roo, Secretaría de Gobernación, 2007.

Recibido: 24/11/2014. Aceptado: 04/03/2015 